Article

\title{
Mutated Channelrhodopsins with Increased Sodium and Calcium Permeability
}

\author{
Xiaodong Duan, Georg Nagel * and Shiqiang Gao *(D) \\ Botanik I, Julius-Maximilians-Universität Würzburg, Biozentrum, Julius-von-Sachs-Platz 2, \\ D-97082 Würzburg, Germany; xiaodong.duan@stud-mail.uni-wuerzburg.de \\ * Correspondence: nagel@uni-wuerzburg.de (G.N.); gao.shiqiang@uni-wuerzburg.de (S.G.)
}

Received: 14 January 2019; Accepted: 12 February 2019; Published: 15 February 2019

Featured Application: This study provides optogenetic tools with superior photocurrent amplitudes and high $\mathrm{Na}^{+}$and $\mathrm{Ca}^{2+}$ conductance.

\begin{abstract}
Background: After the discovery and application of Chlamydomonas reinhardtii channelrhodopsins, the optogenetic toolbox has been greatly expanded with engineered and newly discovered natural channelrhodopsins. However, channelrhodopsins of higher $\mathrm{Ca}^{2+}$ conductance or more specific ion permeability are in demand. (2) Methods: In this study, we mutated the conserved aspartate of the transmembrane helix 4 (TM4) within Chronos and PsChR and compared them with published ChR2 aspartate mutants. (3) Results: We found that the ChR2 D156H mutant (XXM) showed enhanced $\mathrm{Na}^{+}$and $\mathrm{Ca}^{2+}$ conductance, which was not noticed before, while the D156C mutation (XXL) influenced the $\mathrm{Na}^{+}$and $\mathrm{Ca}^{2+}$ conductance only slightly. The aspartate to histidine and cysteine mutations of Chronos and $P_{s} \mathrm{ChR}$ also influenced their photocurrent, ion permeability, kinetics, and light sensitivity. Most interestingly, PsChR D139H showed a much-improved photocurrent, compared to wild type, and even higher $\mathrm{Na}^{+}$selectivity to $\mathrm{H}^{+}$than XXM. PSChR D139H also showed a strongly enhanced $\mathrm{Ca}^{2+}$ conductance, more than two-fold that of the CatCh. (4) Conclusions: We found that mutating the aspartate of the TM4 influences the ion selectivity of channelrhodopsins. With the large photocurrent and enhanced $\mathrm{Na}^{+}$selectivity and $\mathrm{Ca}^{2+}$ conductance, $\mathrm{XXM}$ and $\mathrm{Ps} \mathrm{ChR} \mathrm{D} 139 \mathrm{H}$ are promising powerful optogenetic tools, especially for $\mathrm{Ca}^{2+}$ manipulation.
\end{abstract}

Keywords: optogenetics; channelrhodopsins; sodium; calcium; DC gate

\section{Introduction}

Channelrhodopsins were first discovered and characterized from C. reinhardtii [1,2]. After the showing of light-switched large passive cation conductance in HEK293 and BHK cells by Nagel et al., the ChR2 (C. reinhardtii channelrhodopsin-2) was immediately applied in neuroscience by several independent groups for studies in hippocampal neurons [3,4], Caenorhabditis elegans [5], inner retinal neurons [6], and PC12 cells [7]. H134R (histidine to arginine mutation at position 134) was the first ChR2 gain-of-function mutant which showed enhanced plasma membrane expression and larger stationary photocurrents in comparison to ChR2 wild type [5].

Other variants came out in rapid sequence, either of natural origin or mutated and engineered. The calcium translocating channelrhodopsin CatCh (a ChR2 leucine to cysteine mutation at position 132, L132C) showed improved $\mathrm{Ca}^{2+}$ conductivity together with a larger photocurrent and higher light sensitivity [8]. Newly discovered Chronos (Stigeoclonium helveticum channelrhodopsin $=S h \mathrm{ChR}$ ) and Chrimson ( $\mathrm{CnChR1}$ from Chlamydomonas noctigama) showed a faster channel closing and a red-shifted action spectrum, respectively [9]. An E90R (glutamate to arginine mutation at position 90) 
point mutation could extend the cation conductance of ChR2 to additional anion conductance [10]. Naturally, very specific anion conductive channelrhodopsins, GtACR1 and GtACR2 (Guillardia theta anion channelrhodopsin 1 and 2), were discovered afterwards [11].

Mutation of ChR2 C128 (cysteine at position 128) to threonine (T), alanine (A), and serine (S) slowed the closing kinetics dramatically [12-14]. Mutation of ChR2 D156 (cysteine at position 156) to alanine also decreased the closing kinetics [14]. Spectral studies suggested that a putative hydrogen bond between C128 and D156 could be an important structural determinant of the channel's closing reaction [14] or might represent the valve of the channel [15]. Thus, hydrogen bond-linked D156 and C128 was proposed as the putative gate buried in the membrane ("DC gate") [14,15]. But the first channelrhodopsin structure was a chimaera (C1C2) of truncated ChR1 and ChR2, and the distances between C167 (corresponding to C128 in ChR2) and D195 (corresponding to D156 in ChR2) are too far away to be associated by a hydrogen bond [16]. However, the recently solved structure of wild type ChR2 revealed a water molecule between C128 and D156 to bridge them, indeed, by hydrogen bonds [17].

Mutation of the DC gate has a strong effect on the open channel lifetime. The ChR2 D156C (aspartate to cysteine mutation at position 134) mutant (XXL) generated very large photocurrents and is 1000-fold more light-sensitive than wild type ChR2 in Drosophila larvae [18]. The ChR2 $\mathrm{D} 156 \mathrm{H}$ (aspartate to histidine mutation at position 134) mutant (XXM) also showed a superior photo stimulation efficiency with faster kinetics than XXL, which made it an ideal optogenetic tool for Drosophila neurobiological studies [19].

The aspartate D156 in ChR2 is located close to the protonated retinal Schiff base (RSBH+). Thus, mutations of D156 logically have strong effects on the open channel lifetime by influencing the protonation state of the retinal Schiff base. However, the water-bridged C128 and D156 are not in the putative ion pore proposed by Volkov et al. [17]. And no attention had been paid to the potential changes of ion selectivity by DC gate mutations.

In this study, we compared the ion selectivity of our previously published XXL and XXM and found that XXM showed a four-fold increased $\mathrm{Na}^{+}$selectivity over $\mathrm{H}^{+}$together with a two-fold increased $\mathrm{K}^{+}$selectivity over $\mathrm{H}^{+}$, compared to wild type ChR2. Based on this finding, we made further aspartate to histidine and cysteine mutations of PsChR (Platymonas subcordiformis channelrhodopsin) [20] and Chronos [9]. PsChR wild type was already reported to be highly $\mathrm{Na}^{+}$ conductive and indeed showed a six-fold increased $\mathrm{Na}^{+}$and $\mathrm{K}^{+}$selectivity over $\mathrm{H}^{+}$compared to wild type ChR2 in our measurements. But the $\mathrm{D} 139 \mathrm{H}$ mutation of $P_{s} \mathrm{ChR}$ further increased the $\mathrm{Na}^{+}$ selectivity over $\mathrm{H}^{+}$five-fold. Furthermore, $P_{s} \mathrm{ChR}$ D139H showed a 5-fold larger photocurrent than PsChR wt.

We further compared the $\mathrm{Ca}^{2+}$ permeability of these mutants. XXM showed an increased $\mathrm{Ca}^{2+}$ current compared to CatCh [8]. PSChR wild type already showed a good $\mathrm{Ca}^{2+}$ current, but the D139H mutation further increased the $\mathrm{Ca}^{2+}$ current. We concluded that the mutant $P s \mathrm{ChR}$ D139H would be a powerful tool for optogenetic $\mathrm{Ca}^{2+}$ manipulation.

\section{Materials and Methods}

\subsection{Plasmids and RNA Generation for Xenopus Laevis Oocyte Expression}

ChR2, XXM, and XXL in the pGEMHE vector were described in previous studies $[18,19,21]$. PsChR (from Platymonas subcordiformis, Accession No.: JX983143) and Chronos (from Stigeoclonium helveticum, Accession No.: KF992040) were synthesized by GeneArt Strings DNA Fragments (Life Technologies, Thermo Fisher Scientific), according to the published amino acid sequences, with the codon usage optimized to Mus musculus. The synthesized DNA segment was inserted into the pGEMHE vector with N-terminal BamHI and C-terminal XhoI restriction sites. Yellow fluorescent protein (YFP), together with a plasma membrane trafficking signal (KSRITSEGEYIPLDQIDINV) [22] beforehand and an ER export signal (FCYENEV) [22] afterward, the YFP was attached to the C-terminal 
end. Mutations were made by QuikChange Site-Directed Mutagenesis. The sequence was confirmed by DNA sequencing. Plasmids were linearized by NheI digestion and used for in vitro generation of cRNA with the AmpliCap-MaxT7 High Yield Message Maker Kit (Epicentre Biotechnologies).

\subsection{Two-Electrode Voltage-Clamp Recordings of Xenopus Laevis Oocytes}

cRNA-injected oocytes were incubated in ND96 solution $(96 \mathrm{mM} \mathrm{NaCl}, 5 \mathrm{mM} \mathrm{KCl}, 1 \mathrm{mM}$ $\mathrm{MgCl}_{2}, 1 \mathrm{mM} \mathrm{CaCl}_{2}, 5 \mathrm{mM}$ HEPES, pH 7.4) containing $1 \mu \mathrm{M}$ all-trans-retinal at $16{ }^{\circ} \mathrm{C}$. Two-electrode voltage-clamp (TEVC) recordings were performed with solutions, as indicated in figures, at room temperature. For experiments with external $\mathrm{Ca}^{2+}$, we blocked activation of the $\mathrm{Ca}^{2+}$-activated endogenous chloride channels of oocytes by 1,2-bis(o-aminophenoxy)ethane- $\mathrm{N}, \mathrm{N}, \mathrm{N}^{\prime}, \mathrm{N}^{\prime}$-tetraacetic acid (BAPTA) injection. We injected $50 \mathrm{nl} 200 \mathrm{mM}$ of the fast $\mathrm{Ca}^{2+}$ chelator BAPTA (potassium-salt) into each oocyte ( 10 mM final concentration in the oocyte), incubated for 90 mins at $16^{\circ} \mathrm{C}$ and then performed the TEVC measurement at room temperature. Twenty nanograms of cRNA were injected into Xenopus oocyte for all the constructs. Photocurrents were measured two days after injection. For Figures 1 and 2, measurements were performed in standard solution with $\mathrm{BaCl}_{2}$ instead of $\mathrm{CaCl}_{2}$ (110 mM NaCl, $5 \mathrm{mM} \mathrm{KCl}, 2 \mathrm{mM} \mathrm{BaCl}, 1 \mathrm{mM} \mathrm{MgCl}_{2}, 5 \mathrm{mM}$ HEPES and $\mathrm{pH}$ 7.6).

\subsection{Light Stimulation}

Illumination conditions were different, considering the published action spectra of ChR2, Chronos, and $P_{s} \mathrm{ChR}: 473 \mathrm{~nm}$ for ChR2, XXM, and XXL; $445 \mathrm{~nm}$ for $P_{S} \mathrm{ChR}, P_{S} C h R$ D139H, and $P_{S} C h R$ D139C; 532 $\mathrm{nm}$ for Chronos, Chronos D173H, and Chronos D173C. Lasers were from Changchun New Industries Optoelectronics Technology. Light power was set to $5 \mathrm{~mW} / \mathrm{mm}^{2}$, except for the light sensitivity measurement. The light intensities were measured with a PLUS 2 Power \& Energy Meter (LaserPoint s.r.l). For light sensitivity measurement, applied light intensities ranged from 1.7 to $5000 \mu \mathrm{W} / \mathrm{mm}^{2}$.

\subsection{Protein Quantification by Fluorescence}

All expression levels of channelrhodopsin variants in oocytes were quantified by the fluorescence emission values of the YFP-tagged protein. Fluorescence emission was measured at $538 \mathrm{~nm}$ by a Fluoroskan Ascent microplate fluorometer (Thermo Scientific) with $485 \mathrm{~nm}$ excitation.

\subsection{Fluorescence Imaging}

Fluorescence pictures of Xenopus oocytes were taken under 5x objective with a Leica DM6000 confocal microscope after two days' expression. Oocytes were put in a $35 \times 10 \mathrm{~mm}$ petri dish (Greiner GBO) containing ND96 for imaging. Excitation was done using $496 \mathrm{~nm}$ laser light. Fluorescence emission was detected from $520 \mathrm{~nm}$ to $585 \mathrm{~nm}$.

\subsection{Data Processing}

pClamp 7.0 was used to read out the photocurrent. Figures 1a, 2, 3, 4, 5a and A1a were made with OriginPro 2017. Figures $1 b, 5 b$ and A1b were made with GraphPad Prism. Tables 1 and 2 were made with Microsoft Excel. Sequence alignment in Appendix B was performed by BioEdit. Closing time was determined by biexponential fit. Light sensitivity curves were fitted with Hill equation. All values were plotted or presented with mean values, and error bars represent the standard deviations (SD) or standard error mean (SEM), as indicated in each figure. Statistical analysis was done by $t$ test within GraphPad Prism. Differences were considered significant at $p<0.05{ }^{* * *}=p<0.001{ }^{* *}=p<0.01$, $*=p<0.05$. 

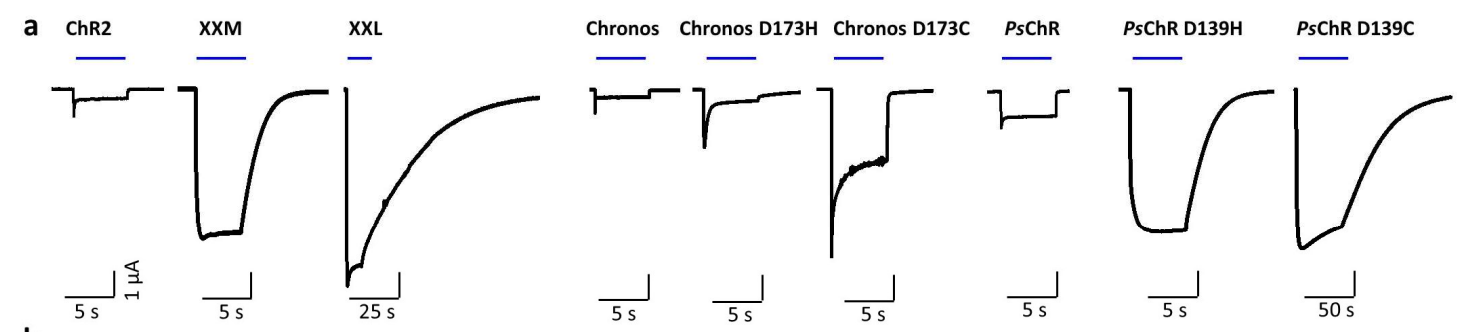

b
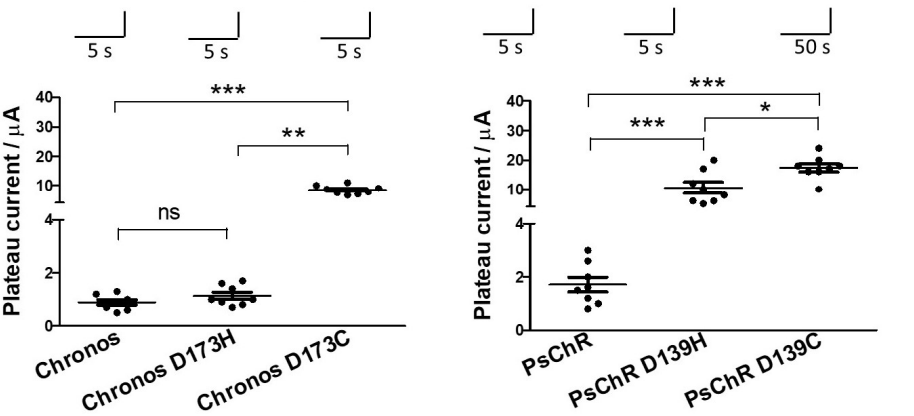

Figure 1. Comparison of $\mathrm{ChR} 2, P_{s} \mathrm{ChR}$, and Chronos variants. (a) Representative photocurrent traces of ChR2, PsChR, Chronos, and their mutants. (b) Comparison of stationary photocurrents of above channelrhodopsin variants. All data points were plotted in the figure and mean \pm standard error mean (SEM) $(n=7-8)$ was indicated.
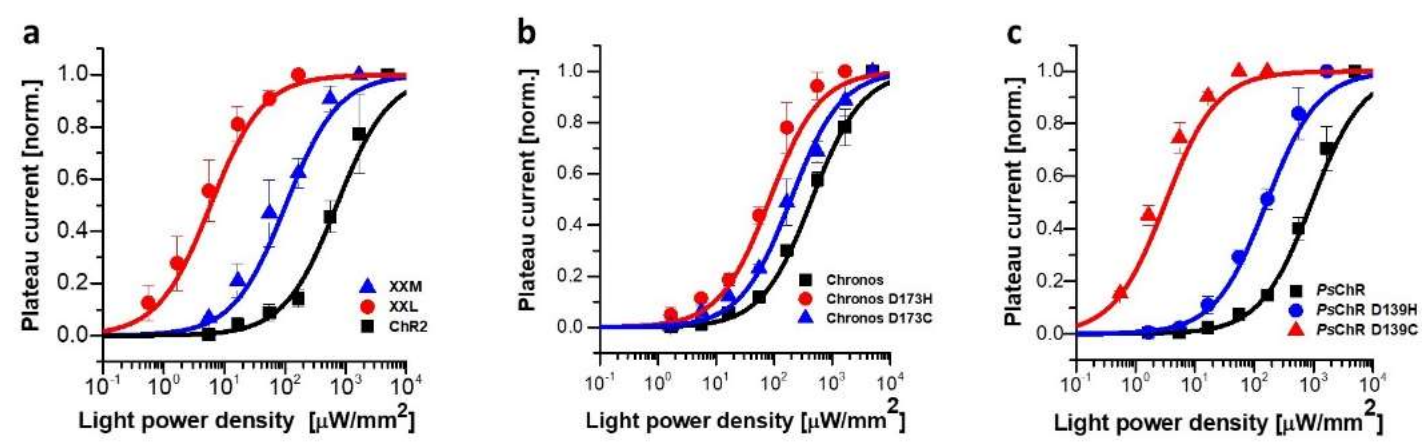

Figure 2. Comparing the light sensitivities of ChR2, $P_{S} C h R$, and Chronos variants. (a) $5 \mathrm{~s}, 30 \mathrm{~s}$, and $100 \mathrm{~s}$ continuous $473 \mathrm{~nm}$ blue light illumination were applied to ChR2, XXM and XXL, respectively. Photocurrent at maximum light power density of each oocyte was normalized as 1. (b) 5 s continuous $532 \mathrm{~nm}$ blue light illumination were applied to Chronos, Chronos D173H, and Chronos D173C. Photocurrent at maximum light power density of each oocyte was normalized as 1 . (c) $5 \mathrm{~s}, 30 \mathrm{~s}$, and 100 s continuous $445 \mathrm{~nm}$ blue light illumination were applied to $P_{s} \mathrm{ChR}, P_{S} \mathrm{ChR}$ D139H, and PsChR D139C. Photocurrent at maximum light power density of each oocyte was normalized as 1 . Photocurrents of XXM, XXL, PsChR D139H, and PsChR D139C were measured at $-60 \mathrm{mV}$ because of the larger current and slower kinetics; other constructs were measured at $-100 \mathrm{mV}$. Data points were presented as mean $\pm \mathrm{SD}, n=3-4$.

\section{Results}

\subsection{Mutating the Conserved Aspartate of TM Helix 4 Influences the Expression, Photocurrent, and Kinetics}

Similar to previously published results $[18,19]$, fluorescence measurements of whole oocyte membranes with YFP-tagged XXM and XXL showed a three-fold increased expression level, compared to ChR2 (Figure A1). The steady-state photocurrents were increased $\sim 30$ - and $\sim 48$-fold for XXM (D156H) and XXL (D156C), respectively, compared to ChR2 (Figure 1 and Table 1). The enhanced photocurrent might have been a comprehensive outcome of the higher plasma membrane expression level, higher light-sensitivity, or increased single channel conductance. Both XXM and XXL showed much-prolonged closing kinetics, leading to higher light-sensitivity (Figure 1a and Table 1). 


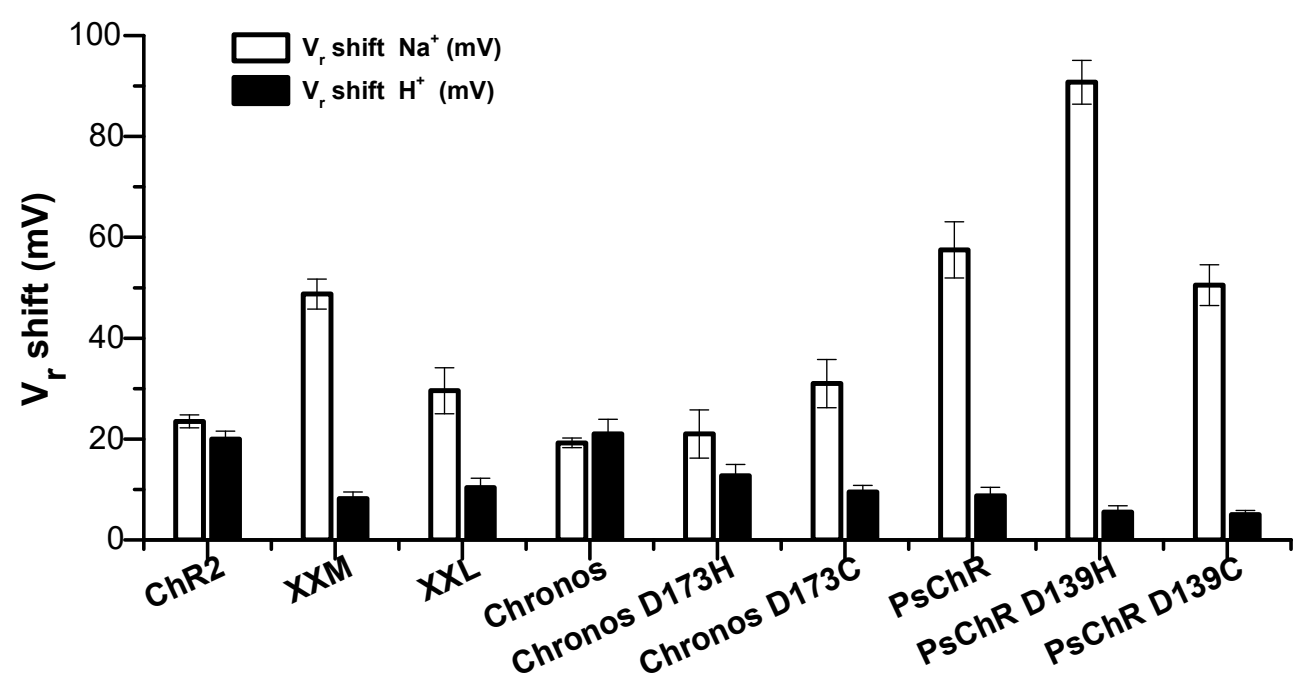

Figure 3. Comparison of $\mathrm{Na}^{+}$and $\mathrm{H}^{+}$permeabilities of $\mathrm{ChR} 2$, Chronos, $P s \mathrm{ChR}$, and their mutants. Reversal potentials $\left(\mathrm{V}_{\mathrm{r}}\right)$ were determined after photocurrent measurements from $-90 \mathrm{mV}$ to $+10 \mathrm{mV}$. Reversal potential shift for $\mathrm{Na}^{+}$was calculated by the reversal potential differences in two outside buffers containing $120 \mathrm{mM} \mathrm{NaCl}$ pH 7.6 and $1 \mathrm{mM} \mathrm{NaCl} \mathrm{pH} \mathrm{7.6.} \mathrm{Reversal} \mathrm{potential} \mathrm{shift} \mathrm{for} \mathrm{H}^{+}$was determined by the reversal potential differences in two outside buffers of $\mathrm{pH} 7.6$ and 9.6 containing $120 \mathrm{mM} \mathrm{NaCl}$. Data points were presented as mean $\pm \mathrm{SD}, n=4-6$.

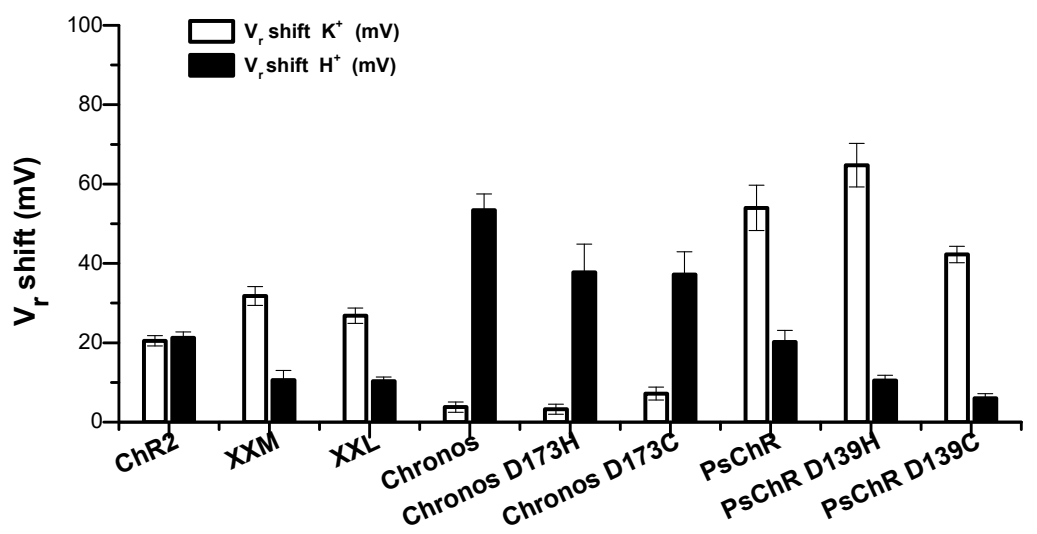

Figure 4. Comparison of $\mathrm{K}^{+}$and $\mathrm{H}^{+}$permeabilities of ChR2, Chronos, $P_{s} \mathrm{ChR}$, and their mutants. Reversal potentials were determined after photocurrent measurements from $-90 \mathrm{mV}$ to $+10 \mathrm{mV}$. Reversal potential shift for $\mathrm{K}^{+}$was calculated by the reversal potential differences in two outside buffers containing $120 \mathrm{mM} \mathrm{KCl} \mathrm{pH} 7.6$ and $1 \mathrm{mM} \mathrm{KCl} \mathrm{pH} \mathrm{7.6.} \mathrm{Reversal} \mathrm{potential} \mathrm{shift} \mathrm{for} \mathrm{H}^{+}$was determined by the reversal potential differences in two outside buffers of $\mathrm{pH} 7.6$ and 9.6 containing $120 \mathrm{mM} \mathrm{KCl}$. Data points were presented as mean \pm SD, $n=4-6$.

We further synthesized Chronos [9] and $P_{S} C h R$ [20] and characterized the corresponding aspartate to cysteine, and the histidine mutations as the aspartate in transmembrane helix 4 (TM4) were conserved in all three channelrhodopsins (Appendix B). Chronos D173C, D173H, and PsChR D139H, D139C, all showed an increased expression level, compared to their wild type (Figure 1a). All mutants also showed increased light-sensitivities along with prolonged off kinetics (Figure 2 and Table 1). Chronos D173C, PSChR D139H and PsChR D139C showed dramatically increased photocurrents while the Chronos D173H was similar to the wild type Chronos (Figure 1 and Table 1). Among these variants, $P_{S} C h R$ D139C was the most light-sensitive with an effective light power density (LPD) for $50 \%$ photocurrent $\left(\mathrm{EPD}_{50}\right)$ of $\sim 3.2 \mu \mathrm{W} / \mathrm{mm}^{2}$, which was $\sim 250$ times more sensitive than $P_{S} \mathrm{ChR}$ (Figure 2 and Table 1). The $\mathrm{EPD}_{50}$ for $\mathrm{XXL}$ was $\sim 5.4 \mu \mathrm{W} / \mathrm{mm}^{2}$, which was $\sim 130$ times more sensitive than ChR2 (Figure 2 and Table 1). 

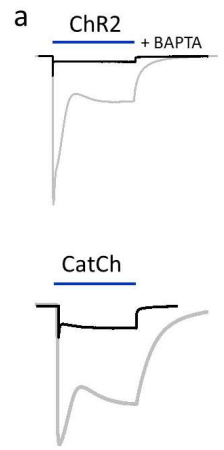
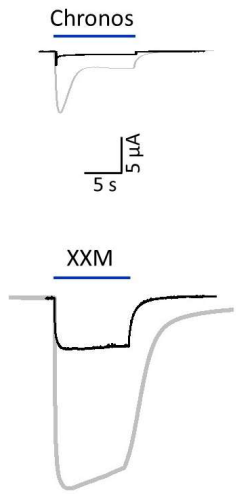

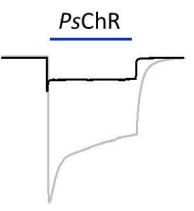

PsChR D139H

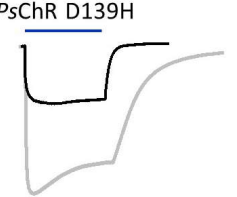

b

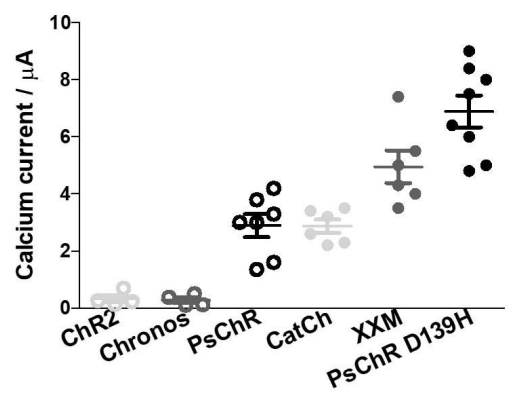

Figure 5. Calcium permeabilities of selected channelrhodopsin variants.

(a)

Photocurrent traces of different channelrhodopsins before (grey) and after (black) 1,2-bis(o-aminophenoxy)ethane- $\mathrm{N}, \mathrm{N}, \mathrm{N}^{\prime}, \mathrm{N}^{\prime}$-tetraacetic acid (BAPTA) injection. Measurements were done in $80 \mathrm{mM} \mathrm{CaCl}_{2} \mathrm{pH} 9.0$ at $-100 \mathrm{mV}$. Blue bars indicate light illumination. (b) Comparison of calcium permeability of ChR2 (light grey), Chronos (dark grey), PsChR (black), CatCh (light grey), XXM (dark grey), and PsChR D139H (black). All data points were plotted in the figure and mean \pm SEM was indicated.

Table 1. Basic properties of ChR2, PsChR, and Chronos variants.

\begin{tabular}{|c|c|c|c|c|c|}
\hline & \multirow{2}{*}{ Expression * } & \multirow{2}{*}{$\mathbf{I}_{\mathrm{s}}$} & \multicolumn{2}{|c|}{ Closing Time (ms) } & \multirow{2}{*}{$\begin{array}{c}\mathrm{EPD}_{50} \\
\left(\mu \mathrm{W} / \mathrm{mm}^{2}\right)\end{array}$} \\
\hline & & & $\tau_{1}\left(\%^{\ddagger}\right)$ & $\tau_{2}(\%)$ & \\
\hline ChR2 & $1 x^{+}$ & $1 x^{+}$ & $7.5 \pm 0.5(>98)$ & - & 710 \\
\hline XXM & $2.7 \times$ & $30 \times$ & $80 \pm 5.5(8)$ & $1100 \pm 110(92)$ & 90 \\
\hline XXL & $3 \times$ & $48 \times$ & - & $71000 \pm 2900(>96)$ & 5.4 \\
\hline Chronos & $1 x^{+}$ & $1 x^{+}$ & $2.8 \pm 0.3(>99)$ & - & 500 \\
\hline $\begin{array}{c}\text { Chronos } \\
\text { D173H }\end{array}$ & $2.2 \times$ & $1.2 \times$ & $1400 \pm 160(56)$ & - & 84 \\
\hline Chronos D173C & $2.6 \times$ & $10 \times$ & $22 \pm 1.3(85)$ & $130 \pm 16(15)$ & 190 \\
\hline$P_{s} \mathrm{ChR}$ & $1 x^{+}$ & $1 x^{+}$ & $8.5 \pm 0.6(>98)$ & - & 810 \\
\hline PsChR D139H & $2.2 \times$ & $6 \times$ & $37 \pm 2.7(14)$ & $810 \pm 54(86)$ & 160 \\
\hline PsChR D139C & $3.1 \times$ & $11 \times$ & $3.4 \pm 0.8(4)$ & $74000 \pm 4300(96)$ & 3.2 \\
\hline
\end{tabular}

${ }^{\dagger}$, expression or photocurrent of corresponding wild type was normalized as $1 \times$. Is, stationary (plateau) current. $\ddagger_{\text {, }}$ as most ChRs exhibit biphasic off-kinetics which comprised a fast and a slow component, here the \% indicated the percentage of the amplitude of the fast $\left(\tau_{1}\right)$ or slow $\left(\tau_{2}\right)$ component to the whole photocurrent. Data are shown as mean \pm SEM, $n=4-5$. Values are presented as approximates. *, expression level was calculated from the data of fluorescence value in Appendix A Figure A1.

Table 2. Ion selectivity of $\mathrm{ChR} 2, P_{s} \mathrm{ChR}$, and Chronos variants.

\begin{tabular}{|c|c|c|c|c|c|c|c|}
\hline & \multicolumn{4}{|c|}{ Reversal Potential Shift (mV) } & \multicolumn{3}{|c|}{ Permeability Ratio } \\
\hline ChR2 & $24 \pm 0.6$ & $20 \pm 0.7$ & $21 \pm 0.6$ & $22 \pm 0.8$ & $3.1 \times 10^{-7}$ & $2.5 \times 10^{-7}$ & 1.2 \\
\hline XXM & $49 \pm 1.5$ & $8.2 \pm 0.6$ & $32 \pm 1.0$ & $11 \pm 1.1$ & $12 \times 10^{-7}$ & $5 \times 10^{-7}$ & 2.2 \\
\hline XXL & $30 \pm 2$ & $10 \pm 0.8$ & $27 \pm 0.8$ & $10 \pm 0.4$ & $4.5 \times 10^{-7}$ & $3.8 \times 10^{-7}$ & 1.2 \\
\hline PsChR & $58 \pm 2.8$ & $8.8 \pm 5.5$ & $54 \pm 5.7$ & $20 \pm 1.3$ & $18 \times 10^{-7}$ & $16 \times 10^{-7}$ & 1.2 \\
\hline Chronos & $19 \pm 0.4$ & $21 \pm 1.1$ & $3.8 \pm 0.6$ & $53 \pm 1.8$ & $2.3 \times 10^{-7}$ & $0.33 \times 10^{-7}$ & 7.1 \\
\hline Chronos D173H & $21 \pm 2.4$ & $14 \pm 1.1$ & $3.3 \pm 0.6$ & $38 \pm 3.6$ & $2.6 \times 10^{-7}$ & $0.28 \times 10^{-7}$ & 9.4 \\
\hline Chronos D173C & $31 \pm 2.4$ & $9.5 \pm 0.6$ & $7.2 \pm 0.7$ & $37 \pm 2.6$ & $5 \times 10^{-7}$ & $0.67 \times 10^{-7}$ & 7.3 \\
\hline
\end{tabular}

Reversal potentials and permeability ratio were determined from stationary currents in the indicated solution. Values represent mean $\pm \mathrm{SD}, n=4-6$. Values without $\mathrm{SD}$ are presented as approximates. ${ }^{\dagger}$, with the existence of $120 \mathrm{mM} \mathrm{Na}^{+} . \ddagger$, with the existence of $120 \mathrm{mM} \mathrm{K}^{+}$. 


\subsection{Mutation of the Aspartate in TM4 Influences the $\mathrm{Na}^{+}$Permeability}

The potential influence on ion selectivity by mutating ChR2 D156 was not reported. To investigate this, we measured the photocurrent at different potentials and calculated the reversal potential shift of these mutants, when systematically changing bath solutions with different $\mathrm{pH}$ and $\mathrm{Na}^{+}$ or $\mathrm{K}^{+}$concentrations.

ChR2 is a non-selective cation channel which is mostly permeable to $\mathrm{H}^{+}$[2]. Both changing extracellular $\mathrm{pH}$ from 7.6 to 9.6 and changing extracellular $\mathrm{Na}^{+}$concentration from $120 \mathrm{mM}$ to $1 \mathrm{mM}$ altered the ChR2 reversal potential (Figure 3). The ChR2 permeability ratio of $\mathrm{Na}^{+}$to $\mathrm{H}^{+}\left(\mathrm{P}_{\mathrm{Na}_{+}} / \mathrm{P}_{\mathrm{H}_{+}}\right)$ was determined as $\mathrm{P}_{\mathrm{Na}+} / \mathrm{P}_{\mathrm{H}+}=3.1 \times 10^{-7}$ (Table 2). Interestingly, D156H (XXM) influenced the $\mathrm{Na}^{+}$ permeability and increased the $\mathrm{P}_{\mathrm{Na}+} / \mathrm{P}_{\mathrm{H}+}$ four times, while D156C $(X X L)$ changed the $\mathrm{P}_{\mathrm{Na}+} / \mathrm{P}_{\mathrm{H}+}$ only slightly (Table 2).

Chronos is more permeable to $\mathrm{H}^{+}$than ChR2 with a $\mathrm{P}_{\mathrm{Na}+} / \mathrm{P}_{\mathrm{H}+}=2.3 \times 10^{-7}$ (Table 2). The D173H mutation did not obviously change this, and D173C increased the $\mathrm{P}_{\mathrm{Na}+} / \mathrm{P}_{\mathrm{H}+}$ slightly to $5 \times 10^{-7}$ (Figure 3 and Table 2). PsChR was reported to be highly $\mathrm{Na}^{+}$conductive [20]. Changing the outside $\mathrm{Na}^{+}$concentration from $120 \mathrm{mM}$ to $1 \mathrm{mM}$ greatly influenced its photocurrent. The inward photocurrent was nearly abolished at $1 \mathrm{mM} \mathrm{Na}^{+} \mathrm{pH}$ 7.6, and we determined the $P s C h R \mathrm{P}_{\mathrm{Na}+} / \mathrm{P}_{\mathrm{H}+}$ to be $18 \times 10^{-7}$, which was even higher than that of XXM (Figure 3 and Table 2). The D139H mutation increased the $\mathrm{P}_{\mathrm{Na}+} / \mathrm{P}_{\mathrm{H}+}$ even five-fold more, to $90 \times 10^{-7}$, while the D139C mutation decreased the $\mathrm{P}_{\mathrm{Na}+} / \mathrm{P}_{\mathrm{H}+}$ slightly (Figure 3 and Table 2).

Among the tested constructs, $P_{S} \mathrm{ChR}$ D139H was the most $\mathrm{Na}^{+}$permeable channelrhodopsin with a large photocurrent and, to our knowledge, the most $\mathrm{Na}^{+}$-permeable channelrhodopsin ever reported.

\subsection{Mutation of the Aspartate in TM4 Influences the $\mathrm{K}^{+}$Permeability}

As tools for light-induced depolarization, ideal cation-permeable channelrhodopsins should be more $\mathrm{Na}^{+}$conductive and less $\mathrm{K}^{+}$conductive, because $\mathrm{K}^{+}$efflux across the plasma membrane would lead to a more hyperpolarized membrane potential. To test the potential influences on $\mathrm{K}^{+}$permeability of different mutations, we measured photocurrents and calculated the reversal potential shift of these mutants when systematically changing bath solutions from $120 \mathrm{mM} \mathrm{K}^{+}$to $1 \mathrm{mM} \mathrm{K}^{+}$in comparison to changing $\mathrm{pH}$ from 7.6 to 9.6.

ChR2 had a slightly weaker $\mathrm{K}^{+}$conductance in comparison to $\mathrm{Na}^{+}$with a $\mathrm{P}_{\mathrm{Na}+} / \mathrm{P}_{\mathrm{K}+}=1.2$. XXL increased the $\mathrm{Na}^{+}$and $\mathrm{K}^{+}$permeability slightly and equally. XXM increased the $\mathrm{Na}^{+}$permeability more than that for $\mathrm{K}^{+}$, and the $\mathrm{P}_{\mathrm{Na}+} / \mathrm{P}_{\mathrm{K}+}$ of XXM reached 2.2 (Figure 4 and Table 2). PsChR showed a higher $\mathrm{Na}^{+}$permeability, together with an enhanced $\mathrm{K}^{+}$permeability in comparison to that for $\mathrm{H}^{+}$, with a similar $\mathrm{P}_{\mathrm{Na}+} / \mathrm{P}_{\mathrm{K}+}$ as ChR2 (Figure 4 and Table 2). Interestingly, the D139H mutation increased the $\mathrm{Na}^{+}$permeability five-fold, while changing the $\mathrm{K}^{+}$permeability only 1.6 -fold, thus the $\mathrm{P}_{\mathrm{Na}+} / \mathrm{P}_{\mathrm{K}+}$ of $P_{s} C h R$ D139H increased to 3.5 (Figure 4 and Table 2). The increased $\mathrm{P}_{\mathrm{Na}+} / \mathrm{P}_{\mathrm{K}+}$ makes $P_{s} \mathrm{ChR}$ D139H even more suitable as a depolarization tool.

Chronos, Chronos D173H, and Chronos D173C had much lower $\mathrm{K}^{+}$permeability and the highest $\mathrm{P}_{\mathrm{Na}+} / \mathrm{P}_{\mathrm{K}+}$ value among the tested constructs (Figure 4 and Table 2 ). However, the $\mathrm{H}^{+}$permeability was the highest for all Chronos variants (Table 2).

\subsection{Mutation of the Aspartate in TM4 Influences the $\mathrm{Ca}^{2+}$ Permeability}

As obvious impacts of mutation of the conserved aspartate in TM4 on ion selectivity were observed, we further compared the $\mathrm{Ca}^{2+}$ permeability of these mutants, considering the importance of $\mathrm{Ca}^{2+}$ in biological systems. Due to the existence of $\mathrm{Ca}^{2+}$-activated chloride channels in Xenopus oocytes [23], BAPTA was injected into the oocyte to a final concentration of $\sim 10 \mathrm{mM}$, to block the $\mathrm{Ca}^{2+}$-induced chloride current (Figure 5). Then the photocurrents at $-100 \mathrm{mV}$ were measured in outside solution containing $80 \mathrm{mM} \mathrm{CaCl}_{2}$ at $\mathrm{pH}$ 9.0. At $-100 \mathrm{mV}$ and $\mathrm{pH} 9$, no net $\mathrm{H}^{+}$current could be observed and the inward photocurrent was then only from the $\mathrm{Ca}^{2+}$ influx. 
ChR2 showed a robust composite photocurrent with $80 \mathrm{mM} \mathrm{CaCl}_{2}$ at $\mathrm{pH} 9.0$ and $-100 \mathrm{mV}$, which was dramatically reduced to the pure $\mathrm{Ca}^{2+}$ current after injection of $10 \mathrm{mM}$ BAPTA (Figure 5a), as reported previously [2]. Both Chronos and ChR2 showed small $\mathrm{Ca}^{2+}$ photocurrents (Figure 5a). ChR2 L132C (CatCh) showed an increased $\mathrm{Ca}^{2+}$ photocurrent, compared to ChR2 (Figure 5), as previously reported [8]. Astonishingly, XXM also showed an increased $\mathrm{Ca}^{2+}$ photocurrent, even higher than that of CatCh (Figure 5). PSChR D139H showed the highest $\mathrm{Ca}^{2+}$ photocurrent, which on average was more than two times higher than that of CatCh (Figure 5b).

\section{Discussion}

Channelrhodopsins, originating from different organisms, show quite different properties with respect to kinetics, action spectrum, and ion selectivity. Such changes can also be engineered by point mutations. In this study we compared the properties of ChR2, Chronos [9], $P_{S} \mathrm{ChR}$ [20], and their corresponding mutants of the aspartate in TM4 (DC gate aspartate).

Generally, the aspartate to histidine or cysteine mutations of the three channelrhodopsins increased the expression level (probably because the mutant became more stable against degradation [21]) and slowed the closing kinetics. Nearly all mutants showed a much-increased photocurrent, probably because of a much-prolonged open state or enhanced single channel conductance, with only Chronos D173H as an exception.

The tools with slowed kinetics are unfavorable for ultra-fast multiple stimulation but preferred for experiments which require low light and longtime stimulation. The prolonged open times were accompanied by elevated light sensitivities. Among the tested constructs, PsChR D139C and XXL became $\sim 220$ times and $\sim 130$ times more sensitive than ChR2. If slow closing would have not been a problem nor even desired, the more light-sensitive channelrhodopsins would have been ideal for efficient deep brain stimulation with infrared light via upconversion nanoparticles (UCNPs) [24]. These tools need to be further tested in mammalian systems for a broader field application.

Furthermore, we investigated the influence of mutation of the aspartate in TM4 on ion selectivity. We found that aspartate to histidine mutation of ChR2 and PsChR increased the $\mathrm{Na}^{+}$and $\mathrm{Ca}^{2+}$ permeability dramatically. To test the $\mathrm{Ca}^{2+}$ current, we used BAPTA to block the $\mathrm{Ca}^{2+}$-activated endogenous chloride channels of oocytes. The fast $\mathrm{Ca}^{2+}$ chelator BAPTA may have been altering the ion currents in more ways [25]. However, as we could see from the kinetics in Figure 5a that the $\mathrm{Cl}^{-}$ current (which shows a slower off kinetics) was well-blocked. Then we could reliably compare only the photocurrent of our channelrhodopsins.

With the large photocurrent, increased $\mathrm{Na}^{+}$permeability, and bigger $\mathrm{Ca}^{2+}$ current, $P s \mathrm{ChR} \mathrm{D} 139 \mathrm{H}$ is a novel powerful optogenetic tool for depolarization and $\mathrm{Ca}^{2+}$ manipulation. Channelrhodopsins with higher $\mathrm{Ca}^{2+}$ currents have the advantage of being "direct" light-gated $\mathrm{Ca}^{2+}$ channels, in contrast to the highly $\mathrm{Ca}^{2+}$-conductive $\mathrm{CNG}$ (cyclic nucleotide-gated) channels which became light-gated channels when fused with bPAC (photoactivated adenylyl cyclase) [26].

In summary, we found that mutating the conserved aspartate in TM4 influenced not only the expression level and kinetics of channel closing but also the ion selectivity; with appropriate mutations, we provided novel optogenetic tools with superior photocurrent amplitudes and high $\mathrm{Na}^{+}$and $\mathrm{Ca}^{2+}$ conductance.

Author Contributions: Conceptualization, S.G. and G.N.; methodology, X.D., S.G. and G.N.; software, X.D. and S.G.; validation, X.D., S.G. and G.N.; formal analysis, X.D. and S.G.; investigation, X.D. and S.G.; resources, X.D., S.G. and G.N.; data curation, X.D. and S.G.; writing—original draft preparation, S.G.; writing-review and editing, X.D., S.G. and G.N.; visualization, X.D. and S.G.; supervision, S.G. and G.N.; project administration, G.N.; funding acquisition, G.N.

Funding: This research was funded by grants from the German Research Foundation to GN (TRR 166/A03 and TR 240/A04). GN acknowledges support provided by the Prix-Louis-Jeantet.

Acknowledgments: We are grateful to Shang Yang for help with some of the cloning work. This publication was funded by the German Research Foundation (DFG) and the University of Wuerzburg in the funding program Open Access Publishing. 
Conflicts of Interest: The authors declare no conflict of interest.

\section{Appendix A}
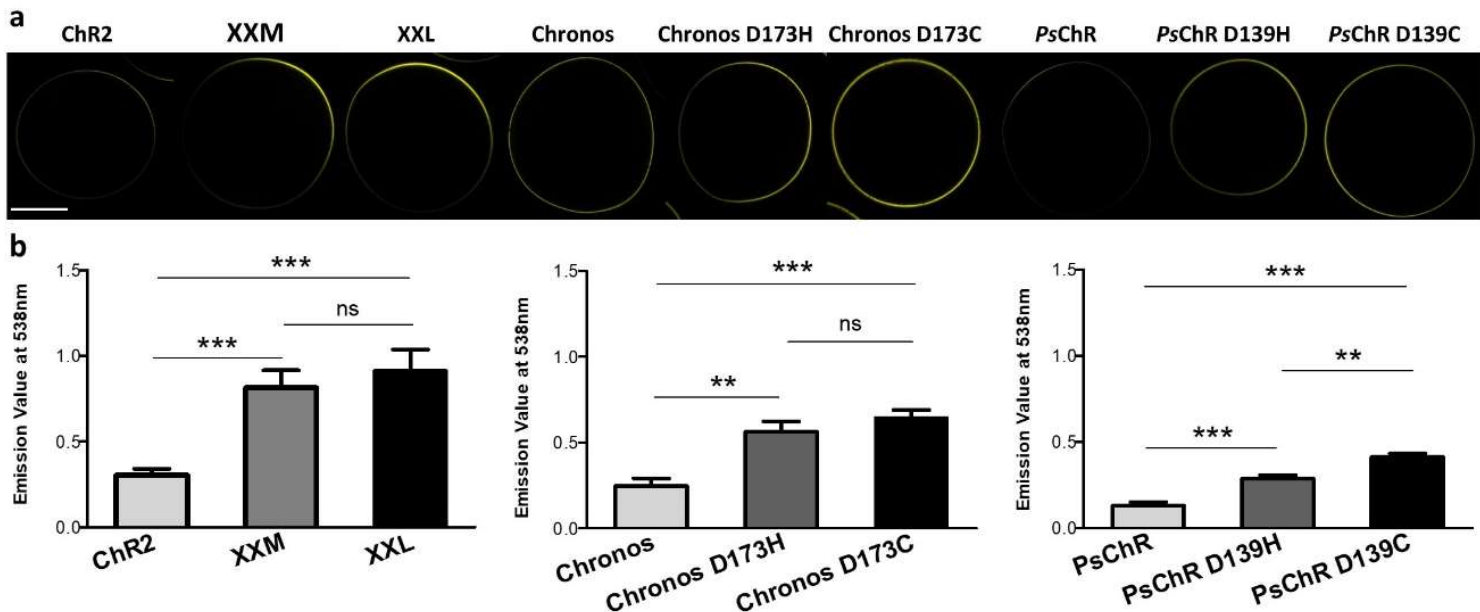

Figure A1. Expression level of ChR2, PSChR, and Chronos variants in Xenopus oocyte. (a) Representative confocal images of all the constructs, scale bar $=500 \mu \mathrm{m}$. (b) Yellow fluorescent protein (YFP) fluorescence emission values from oocytes expressing different channelrhodopsins. Data was shown as mean \pm SEM, $n=5-6$. Pictures and fluorescence emission values were taken and measured 2 days after 20 ng cRNA injection.

\section{Appendix B}

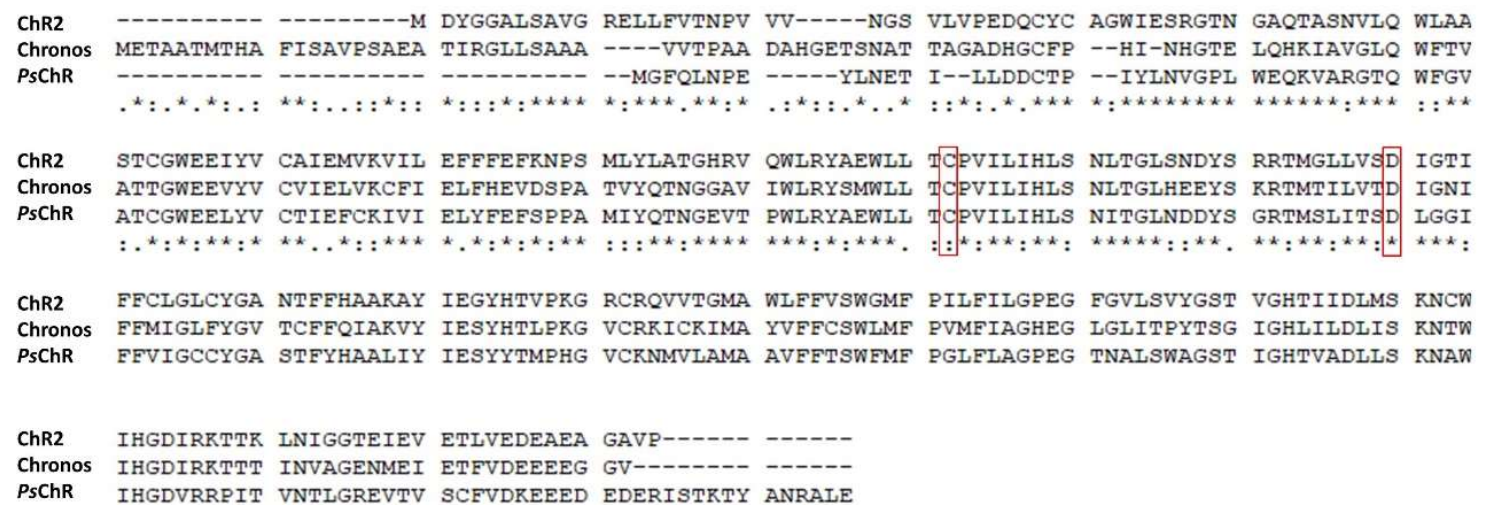

Figure A2. Sequence alignment of ChR2, Chronos, and $P_{S} \mathrm{ChR}$. Conserved cysteine and aspartate of the DC gate were marked in the red box.

\section{References}

1. Nagel, G.; Ollig, D.; Fuhrmann, M.; Kateriya, S.; Mustl, A.M.; Bamberg, E.; Hegemann, P. Channelrhodopsin-1: A light-gated proton channel in green algae. Science 2002, 296, 2395-2398. [CrossRef]

2. Nagel, G.; Szellas, T.; Huhn, W.; Kateriya, S.; Adeishvili, N.; Berthold, P.; Ollig, D.; Hegemann, P.; Bamberg, E. Channelrhodopsin-2, a directly light-gated cation-selective membrane channel. Proc. Natl. Acad. Sci. USA 2003, 100, 13940-13945. [CrossRef] [PubMed]

3. Boyden, E.S.; Zhang, F.; Bamberg, E.; Nagel, G.; Deisseroth, K. Millisecond-timescale, genetically targeted optical control of neural activity. Nat. Neurosci. 2005, 8, 1263-1268. [CrossRef] [PubMed]

4. Li, X.; Gutierrez, D.V.; Hanson, M.G.; Han, J.; Mark, M.D.; Chiel, H.; Hegemann, P.; Landmesser, L.T.; Herlitze, S. Fast noninvasive activation and inhibition of neural and network activity by vertebrate rhodopsin and green algae channelrhodopsin. Proc. Natl. Acad. Sci. USA 2005, 102, 17816-17821. [CrossRef] [PubMed] 
5. Nagel, G.; Brauner, M.; Liewald, J.F.; Adeishvili, N.; Bamberg, E.; Gottschalk, A. Light activation of channelrhodopsin-2 in excitable cells of Caenorhabditis elegans triggers rapid behavioral responses. Curr Biol. 2005, 15, 2279-2284. [CrossRef] [PubMed]

6. Bi, A.D.; Cui, J.J.; Ma, Y.P.; Olshevskaya, E.; Pu, M.L.; Dizhoor, A.M.; Pan, Z.H. Ectopic expression of a microbial-type rhodopsin restores visual responses in mice with photoreceptor degeneration. Neuron. 2006, 50, 23-33. [CrossRef] [PubMed]

7. Ishizuka, T.; Kakuda, M.; Araki, R.; Yawo, H. Kinetic evaluation of photosensitivity in genetically engineered neurons expressing green algae light-gated channels. Neurosci. Res. 2006, 54, 85-94. [CrossRef]

8. Kleinlogel, S.; Feldbauer, K.; Dempski, R.E.; Fotis, H.; Wood, P.G.; Bamann, C.; Bamberg, E. Ultra light-sensitive and fast neuronal activation with the $\mathrm{Ca}^{2+}$-permeable channelrhodopsin CatCh. Nat. Neurosci. 2011, 14, 513-518. [CrossRef]

9. Klapoetke, N.C.; Murata, Y.; Kim, S.S.; Pulver, S.R.; Birdsey-Benson, A.; Cho, Y.K.; Morimoto, T.K.; Chuong, A.S.; Carpenter, E.J.; Tian, Z.J.; et al. Independent optical excitation of distinct neural populations. Nat. Methods 2014, 11, 972. [CrossRef]

10. Wietek, J.; Wiegert, J.S.; Adeishvili, N.; Schneider, F.; Watanabe, H.; Tsunoda, S.P.; Vogt, A.; Elstner, M.; Oertner, T.G.; Hegemann, P. Conversion of Channelrhodopsin into a Light-Gated Chloride Channel. Sci. 2014, 344, 409-412. [CrossRef]

11. Govorunova, E.G.; Sineshchekov, O.A.; Janz, R.; Liu, X.Q.; Spudich, J.L. Natural light-gated anion channels: A family of microbial rhodopsins for advanced optogenetics. Sci. 2015, 349, 647-650. [CrossRef] [PubMed]

12. Berndt, A.; Yizhar, O.; Gunaydin, L.A.; Hegemann, P.; Deisseroth, K. Bi-stable neural state switches. Nat. Neurosci. 2009, 12, 229-234. [CrossRef]

13. Radu, I.; Bamann, C.; Nack, M.; Nagel, G.; Bamberg, E.; Heberle, J. Conformational changes of channelrhodopsin-2. J. Am. Chem. Soc. 2009, 131, 7313-7319. [CrossRef]

14. Bamann, C.; Gueta, R.; Kleinlogel, S.; Nagel, G.; Bamberg, E. Structural Guidance of the Photocycle of Channelrhodopsin-2 by an Interhelical Hydrogen Bond. Biochem. 2010, 49, 267-278. [CrossRef] [PubMed]

15. Nack, M.; Radu, I.; Gossing, M.; Bamann, C.; Bamberg, E.; von Mollard, G.F.; Heberle, J. The DC gate in Channelrhodopsin-2: crucial hydrogen bonding interaction between C128 and D156. Photochem. Photobiol. Sci. 2010, 9, 194-198. [CrossRef] [PubMed]

16. Kato, H.E.; Zhang, F.; Yizhar, O.; Ramakrishnan, C.; Nishizawa, T.; Hirata, K.; Ito, J.; Aita, Y.; Tsukazaki, T.; Hayashi, S.; et al. Crystal structure of the channelrhodopsin light-gated cation channel. Nat. 2012, 482, 369-374. [CrossRef] [PubMed]

17. Volkov, O.; Kovalev, K.; Polovinkin, V.; Borshchevskiy, V.; Bamann, C.; Astashkin, R.; Marin, E.; Popov, A.; Balandin, T.; Willbold, D.; et al. Structural insights into ion conduction by channelrhodopsin 2. Sci. 2017, 358, eaan8862. [CrossRef]

18. Dawydow, A.; Gueta, R.; Ljaschenko, D.; Ullrich, S.; Hermann, M.; Ehmann, N.; Gao, S.; Fiala, A.; Langenhan, T.; Nagel, G.; et al. Channelrhodopsin-2-XXL, a powerful optogenetic tool for low-light applications. Proc. Natl. Acad. Sci. USA 2014, 111, 13972-13977. [CrossRef]

19. Scholz, N.; Guan, C.; Nieberler, M.; Grotemeyer, A.; Maiellaro, I.; Gao, S.; Beck, S.; Pawlak, M.; Sauer, M.; Asan, E.; et al. Mechano-dependent signaling by Latrophilin/CIRL quenches cAMP in proprioceptive neurons. eLife 2017, 6, e28360. [CrossRef]

20. Govorunova, E.G.; Sineshchekov, O.A.; Li, H.; Janz, R.; Spudich, J.L. Characterization of a highly efficient blue-shifted channelrhodopsin from the marine alga Platymonas subcordiformis. J. Biol. Chem. 2013, 288, 29911-29922. [CrossRef]

21. Ullrich, S.; Gueta, R.; Nagel, G. Degradation of channelopsin-2 in the absence of retinal and degradation resistance in certain mutants. Biol. Chem. 2013, 394, 271-280. [CrossRef] [PubMed]

22. Gradinaru, V.; Zhang, F.; Ramakrishnan, C.; Mattis, J.; Prakash, R.; Diester, I.; Goshen, I.; Thompson, K.R.; Deisseroth, K. Molecular and cellular approaches for diversifying and extending optogenetics. Cell 2010, 141, 154-165. [CrossRef] [PubMed]

23. Boton, R.; Dascal, N.; Gillo, B.; Lass, Y. Two calcium-activated chloride conductances in Xenopus laevis oocytes permeabilized with the ionophore A23187. J. Physiol. 1989, 408, 511-534. [CrossRef] [PubMed]

24. Chen, S.; Weitemier, A.Z.; Zeng, X.; He, L.; Wang, X.; Tao, Y.; Huang, A.J.Y.; Hashimotodani, Y.; Kano, M.; Iwasaki, H.; et al. Near-infrared deep brain stimulation via upconversion nanoparticle-mediated optogenetics. Sci. 2018, 359, 679-684. [CrossRef] [PubMed] 
25. Bootman, M.D.; Allman, S.; Rietdorf, K.; Bultynck, G. Deleterious effects of calcium indicators within cells; an inconvenient truth. Cell Calcium 2018, 73, 82-87. [CrossRef] [PubMed]

26. Beck, S.; Yu-Strzelczyk, J.; Pauls, D.; Constantin, O.M.; Gee, C.E.; Ehmann, N.; Kittel, R.J.; Nagel, G.; Gao, S. Synthetic Light-Activated Ion Channels for Optogenetic Activation and Inhibition. Front. Neurosci. 2018, 12, 643. [CrossRef] [PubMed] 